\title{
Review on the modeling of the laser sintering process for Polyamide 12
}

\author{
*Hanane YAAGOUBI ${ }^{1}$, Hamid ABOUCHADI ${ }^{1}$, Mourad TAHA JANAN ${ }^{1}$, \\ ${ }^{1}$ Laboratory of Applied Mechanics and Technologies (LAMAT), ENSET, STIS Research Center Mohammed V University, Rabat, \\ morocco, *hanane.yaagoubi@um5s.net.ma
}

\begin{abstract}
One of the most promising additive manufacturing techniques is selective laser sintering (SLS) of thermoplastic materials. However, the materials successfully applicable to laser sintering (LS) are very limited today. In this study the exceptional position of polyamide 12 powders is underlined. Several numerical and experimental studies have been carried out to make comparisons between the use of powdered materials for polyamide 12 and other types of polymers during the SLS process. The complexity of this process and the interaction between the different phenomena involved has not been fully understood. In this work we highlight the different models of the selective laser sintering of polyamide 12 as well as their different results in order to better understand the functioning of this process.
\end{abstract}

\section{Introduction}

Polymers are the most transformed powders in SLS but the phenomena linked to these materials seem to be the most complex among all those described in the literature $[1,2,3,4,5,6,7]$. They concern a deep interaction between transfer of heat, mass and momentum as well as chemical modifications of the materials and variation of the mechanical and thermophysical properties (table1). Even if a wide range of amorphous and semi-crystalline thermoplastics have been experimentally tested for the SLS process, commercial applications are today limited to a small number of polymer thermoplastics: mainly polyamide (PA 12 and PA 11), polycarbonate (PC), polystyrene (PS), polyether etherketone (PEEK) and variants thereof. Polymers are characterized by a fairly low sintering temperature $\left(<200^{\circ} \mathrm{C}\right)$ and thermal conductivity (less than $1 \mathrm{~W} / \mathrm{m} \mathrm{K}$ ) so that they can be considered as insulating materials [5].

In this work we are interested in the study of nylon 12 powder for laser sintering was chosen because of its thermal properties (thermal conductivity and diffusivity) which are representative of the typical range of most of the thermoplastics used for rapid prototyping, moreover, the almost spherical grain shape and the medium size distribution are fairly uniform (figure1), allowing an analysis of the agglomeration process.

\section{Modeling of the SLS process}

\subsection{Heat transfer modeling}

Heat transfer during the laser sintering process described by equation $[6,3,5]$.
This heat equation (1) with temperature-dependent and sintering heat conduction properties ( $\mathrm{Cp}$ being the specific heat and, Qv the heat source (W.m-3).

$$
\rho \mathrm{C}_{p} \frac{\partial T}{\partial t}=\nabla \cdot\left(K e^{\times} T \nabla\right)+\mathrm{Qv}
$$

The author [3] the equation of the heat capacity (eq.2), the energy of the solid-liquid change $\Delta \mathrm{Hm}$ is distributed, by a Gaussian law (Bonaccina et al., 1973), between the temperatures $\mathrm{Tms}$ start of fusion and of fusion $\operatorname{Tmf}(\Delta \mathrm{T}=$ Tmf -Tms).

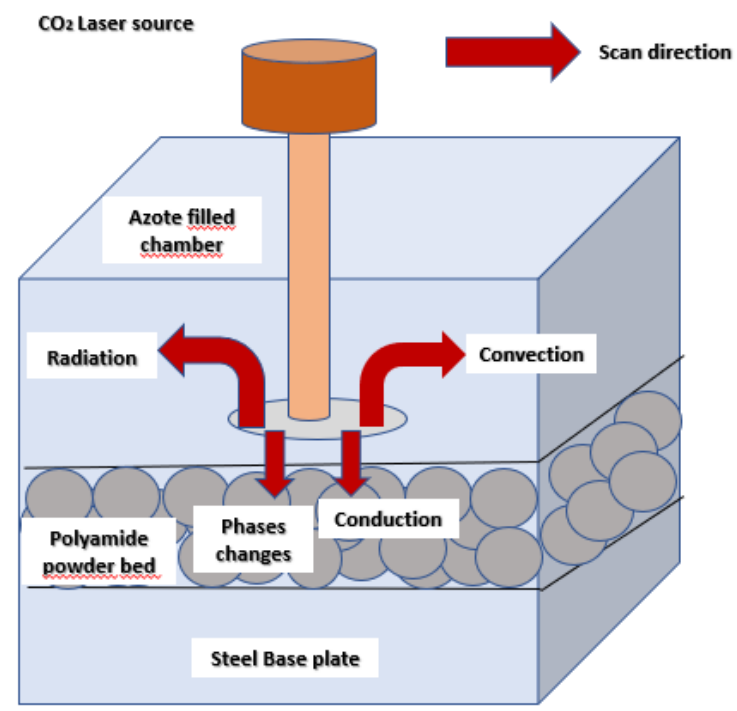

Fig. 1. Thermal exchanges between the laser and the powder bed

* Corresponding author: hanane.yaagoubi@um5s.net.ma 
Table 1. Summary of studies from recent research involving the modeling of SLS for polyamide 12

\begin{tabular}{|c|c|c|c|}
\hline Ref & Research & material & Source \\
\hline [1] & $\begin{array}{l}\text { Characterization and } \\
\text { modeling of non- } \\
\text { isothermal } \\
\text { crystallization of } \\
\text { polyamide } 12 \text { and co- } \\
\text { polypropylene during } \\
\text { the sls process } \\
\end{array}$ & $\begin{array}{l}\text { Polyamide } \\
12 \text { et Co } \\
\text { Polypropyle } \\
\text { ne }\end{array}$ & $\begin{array}{l}\text { A. Amado } \\
\text { \& K. } \\
\text { Wegener } \\
2016\end{array}$ \\
\hline [2] & $\begin{array}{c}\text { Additive } \\
\text { manufacturing: } \\
\text { polymers applicable for } \\
\text { laser sintering (LS) }\end{array}$ & $\begin{array}{c}\text { PA1 } 2 \text { et PA } \\
11\end{array}$ & $\begin{array}{l}\text { Manfred } \\
\text { Schmida, } \\
\text { Konrad } \\
\text { Wegener } \\
2016\end{array}$ \\
\hline [3] & $\begin{array}{c}\text { Experimental and } \\
\text { numerical analysis of } \\
\text { the selective laser } \\
\text { sintering (sls) of PA12 } \\
\text { And PEKK semi- } \\
\text { crystalline polymers }\end{array}$ & $\begin{array}{l}\text { PA12 et } \\
\text { PEEK }\end{array}$ & $\begin{array}{c}\text { Patrice } \\
\text { Peyre, } \\
\text { Yann } \\
\text { Rouchauss } \\
\text { e } \\
2015\end{array}$ \\
\hline [4] & $\begin{array}{c}\text { Thése : Simulation du } \\
\text { procède de fabrication } \\
\text { directe de pièces } \\
\text { thermoplastiques par } \\
\text { fusion laser de poudre }\end{array}$ & PA12 & $\begin{array}{l}\text { Denis } \\
\text { defauchy } \\
2013\end{array}$ \\
\hline & $\begin{array}{l}\text { Etude fondamentale de } \\
\text { la transformation du } \\
\text { polyamide } 12 \text { par } \\
\text { frittage laser : } \\
\text { mécanismes physico- } \\
\text { chimiques et relations } \\
\text { microstructures/proprié } \\
\text { tés }\end{array}$ & PA12 & $\begin{array}{c}\text { Dupuis } \\
2012\end{array}$ \\
\hline [5] & $\begin{array}{l}\text { Experimental analysis } \\
\text { of selective laser } \\
\text { sintering of polyamide } \\
\text { powders from energetic } \\
\text { perspective }\end{array}$ & $\begin{array}{c}\text { Polyamides } \\
\text { DURAFORM } \\
\text { PA12 }\end{array}$ & $\begin{array}{l}\text { Alessandr } \\
\text { o Franco1, } \\
\text { Michele } \\
\text { Lanzett } \\
2012 \\
\end{array}$ \\
\hline [6] & $\begin{array}{l}\text { Simulation of the } \\
\text { densification of } \\
\text { semicrystalline polymer } \\
\text { powders during the } \\
\text { selective laser sintering } \\
\text { process: application to } \\
\text { nylon 12 }\end{array}$ & Nylon 12 & $\begin{array}{l}\text { L. Dong a } \\
\text {, } \\
\text { A.Makradi } \\
\text {,2008 }\end{array}$ \\
\hline [7] & $\begin{array}{l}\text { Selective laser sintering } \\
\text { of a crystalline and a } \\
\text { glass-filled crystalline } \\
\text { polymer: Experiments } \\
\text { and simulations }\end{array}$ & $\begin{array}{l}\text { Nylon } 12 \text { et } \\
\text { glass-filled } \\
\text { nylon } 11\end{array}$ & $\begin{array}{c}\text { T H C } \\
\text { Childs and } \\
\text { A E } \\
\text { Tontowi } \\
2001\end{array}$ \\
\hline
\end{tabular}

$$
\begin{aligned}
& C_{\dot{P}} \\
& =C_{p}(T)+\frac{\Delta H_{m}}{\sqrt{\pi \cdot\left(T_{m f}+T_{m \delta}\right)}} \cdot \exp \left(-\frac{\left(T_{m f}+T_{m \delta}\right)^{2}}{\left(T_{m f}+T_{m \delta}\right)^{2}}\right)
\end{aligned}
$$

Or:

$\mathrm{Tm}$ : is the temperature at the melting point $(\mathrm{K})$,

Tms and $\mathrm{Tmf}(\mathrm{K})$ : the melting temperatures start and end respectively,

$\Delta \mathrm{Hm}$ : the heat of fusion of the enthalpy,

$\mathrm{Cp}(\mathrm{T})$ : considered as a constant value.

During sintering, heat is brought into the powder bed or lost by convection and radiation in the sintering chamber [12]. The energy lost by radiation and convection at the surface of the powder $(z=s)$, where $z$ is the vertical position from the bottom of the powder bed) is described by the following boundary condition:

$$
\begin{aligned}
-\left.K_{e} \frac{\partial T}{\partial Z}\right|_{z=s}= & h\left(T_{a}-T_{\mid z=s}\right) \\
& +\varepsilon_{R} \sigma\left(T_{a}^{4}-\left.T\right|_{z=s} 4\right)
\end{aligned}
$$

Or:

$\mathrm{Ke}$ : is the effective thermal conductivity;

$h$ : is the coefficient of thermal convection, with an assumed value of $\mathrm{h}=25 \mathrm{~d} / \mathrm{sm}^{2} \mathrm{~K}[] ; \varepsilon \mathrm{R}$ is the surface emissivity of the powdered material, assumed to be 0.8 [8];

$\sigma$ : is Stefan-Boltzmann's constant $\sigma=5.68 .10-8 \mathrm{~J} .{ }^{\circ} \mathrm{C}$ 4.m-2.s-1 ;

$\mathrm{Tz}=\mathrm{s}$ : is the temperature on the surface of the powder bed;

Ta: is the preheating temperature.

It is also assumed that there is no heat loss at the bottom of the powder bed $(\mathrm{z}=0)$ :

$-K_{e} \frac{\partial T}{\partial Z} \mid$ bottom $=0$

The effective thermal conductivity ke of nylon 12 is given as a function of the thermal conductivity of the solid material ks and the porosity $\beta$ by the following simple equation [16]:

$k e=k \mathrm{~s}(1-\mathrm{C} \beta)$

Here:

$\mathrm{C}$ : is a constant and the conductivity ks of solid nylon 12 is assumed to be independent of temperature. The values used in the simulations are taken from the work of Childs and Tontowi [16] and are $\mathrm{ks}=0.28 \mathrm{~W} / \mathrm{mK}$ and $\mathrm{C}=1.11$.

According to the author [1] The equation that governs the process of heat transfer from the SLS powder bed inside the construction cylinder during the cooling step is defined as follows: 


$$
\begin{aligned}
& \rho_{\text {eff }}(\alpha \cdot T) C_{P_{e f f}}(\alpha \cdot T) \frac{\partial T}{\partial t} \\
& =\nabla \cdot\left(K_{e f f}(\alpha \cdot T) \cdot \nabla T\right) \\
& +Q \\
& \mathrm{Q}=\left\{\begin{array}{c}
\rho_{e f f}(\alpha \cdot T) \Delta H_{c} \frac{\partial \alpha}{\partial t} \\
0
\end{array}\right.
\end{aligned}
$$

Here:

peff $(\alpha, T)$ : corresponds to the effective density,

Cpeff $(\alpha, \mathrm{T})$ : corresponds to the effective heat capacity

keff $(\alpha, \mathrm{T})$ : corresponds to the effective thermal conductivity.

$\Delta \mathrm{Hc}$ : represents the enthalpy of crystallization. The crystallization rate was previously defined in the following equation:

$$
\frac{\partial \alpha}{\partial t}=n K(T)(1-\alpha)\left[\ln \left(\frac{\alpha}{1-\alpha}\right)\right]^{\frac{n-1}{n}}
$$

The properties of the material are also defined according to the relative crystallinity during the phase change and expressed by the following relationships:

$$
\begin{aligned}
& \rho(\alpha, T)=\alpha \rho_{s}(T)+(1-\alpha) \rho_{m}(T) \\
& C_{p}(\alpha, T)=\alpha C_{P_{S}}(T)+(1-\alpha) C p_{m}(T) \\
& K(\alpha, T)=\alpha K_{s}(T)+(1-\alpha) K_{m}(T)
\end{aligned}
$$

Where the indices $\mathrm{s}$ and $\mathrm{m}$ denote the solid and molten states of the bulk material, respectively. Next, according to Steinberger et al. (2000), the actual material properties can be defined by:

$$
\begin{aligned}
& \rho_{e f f}(\alpha, T)=x_{r e l} \rho(\alpha, T) \\
& C p_{e f f}(\alpha, T)=x_{r e l} c_{p}(\alpha, T)+\left(1-x_{r e l}\right) C p_{N 2} \\
& K_{e f f}(\alpha, T)=x_{r e l} K(\alpha, T)+\left(1-x_{r e l}\right) K_{N 2}
\end{aligned}
$$

Where $\mathrm{CpN} 2$ and $\mathrm{kN} 2$ are the thermal capacity and the thermal conductivity of the atmosphere of the chamber $(95 \%$ N2). xrel represents the material fraction defined for each domain as follows:

$x_{\text {rel }}=\left\{\begin{array}{c}x_{\text {rel.parts }} \\ x_{\text {rel.powderbed }}\end{array}\right.$

\subsection{Distribution of laser radiation intensity}

The SLS system generally uses laser CO2 as a source of thermal energy to induce selective fusion. The intensity distribution over the radius of the laser beam is described by the following relation [13]:

$\mathrm{I}(\mathrm{r}, \mathrm{W})=\left(1-R_{e}\right) I_{0} \exp \left(-\frac{2 r^{2}}{w^{2}}\right)$

Or:

$\mathrm{r}$ : is the radial distance from the center of the laser beam

Re: is the reflectivity of the surface of the powder bed, which is taken to be around 5\% for nylon 12 [13].

The maximum beam intensity $\mathrm{I} 0$ is calculated from the laser power $\mathrm{P}$ and the characteristic radius of the laser intensity profile $\mathrm{W}$ as follows

$$
I_{o p}=\frac{2 P}{\pi w^{2}}
$$

The characteristic radius $w$ is called the Gaussian halfwidth and is linked to the diameter of the beam D as described in $[8,10]$,

$$
W=\frac{D / 2}{2,146}
$$

\subsection{Density simulation}

During the SLS process, the rate of variation of the density of the nylon powder bed 12 is described by the following differential equation [14], which explains the effect of the crystalline phase:

$\frac{\partial \rho}{\partial t}=\left(\rho^{M A X}-\rho\right) \operatorname{Aexp}\left(-\frac{E}{R T}-a \alpha\right)$

Here:

$\rho:$ is the current density;

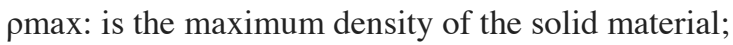

$\mathrm{R}$ : is the universal gas constant; and $\mathrm{E}$ is the activation energy, approximated by $149.66 \mathrm{~kJ} / \mathrm{mol}$. The parameters $\mathrm{A}$ and ax are assumed to be $5 \times 1011 \mathrm{~s}-1$ and 8.0, respectively.

These were obtained by fitting the calculated density to the experimental results of Tontowi and Child. The parameter $\alpha(0 \leq \alpha \leq 1)$ is used to take into account the effect of latent heat during the melting of the crystalline polymer. For this, they used a temperature recovery method [1] which consists in taking the value of $\alpha=1$ until the temperature reaches the melting point and then decreasing it until reaching a leakage value. This reduction of $\alpha$ from 1 to 0 during the fusion is calculated in increments, $\Delta \alpha$ (for each time increment $\Delta \mathrm{t}$ ), using the following equation [15]:

$\Delta \alpha=\frac{C_{p}}{L} \Delta T$ 
Where $\Delta \mathrm{T}=\mathrm{T}-\mathrm{Tm}, \mathrm{T} \geq \mathrm{Tm}, \Delta \mathrm{T}=0, \mathrm{~T}<\mathrm{Tm}$. Here, $\mathrm{Tm}$ is the melting temperature ( $\mathrm{Tm}=459 \mathrm{~K}[6]), \mathrm{Cp}$ is the specific heat, and $\mathrm{L}$ is the latent heat $(\mathrm{L}=1.08 \times 105 \mathrm{~J} /$ $\mathrm{kg}[16])$.

The specific heat of Nylon 12 is assumed to be a linear function of temperature [16], with the specific heat of absolute temperature $\mathrm{Cp}(0)=460 \mathrm{~J} /(\mathrm{kg} \mathrm{K})$.

The porosity $\beta$ of the nylon 12 powder material can change from $50 \%$ (initial powder bed) to the minimum value $\beta \min$ (maximum density material). The porosity is a function of the effective density of the porous material $\rho$ and the density of the solid material $\rho \max =970 \mathrm{~kg} /$ m3:

$$
\beta=\frac{\rho_{\max }-\rho}{\rho_{\max }}
$$

\section{Numerical simulation}

The author [1] characterizes and models the nonisothermal crystallization kinetics of a commercial polyamide (PA12) and a new developed polyolefin (coPP) using differential scanning calorimetry, integrating the Nakamura model into the theory by Hoffmann-Lauritzen. The model results are in good agreement with the experimental data below $90 \%$ and $65 \%$ of the relative crystallization for PA12 and coPP respectively. In addition, a transient FEM simulation of the layer deposition coupling the heat transfer kinetics and crystallization kinetics model describes a constant stepby-step phase change effect per layer linked to a sequence of isothermal and quasi-isothermal states induced by processing conditions.

The author [6] successfully developed a modeling methodology to simulate the SLS process for powders of semi-crystalline polymers (table 2). To do this, we have coupled the constitutive relationships of heat transfer and powder sintering. The effect of the latent heat was taken into account in the constitutive law for sintering using a method of recovery of the temperature. The simulations were carried out for nylon 12 using a three-dimensional finite element analysis. The heat source has been modeled as a heat flux applied to the surface of the powder bed. The predicted results were compared with the experimental results and a reasonably good agreement was found for the density distribution with respect to the applied laser power.

The model was then used to study the parametric relationship between average density and various processing parameters such as laser power, diameter, and speed hatch spacing; and preheating the temperature. In general, non-linear relationships have been found. High densification of the powder bed can be achieved by high laser power and preheating temperature and by low laser speed, laser beam diameter and hatch spacing. However, the non-linearity of the relations obtained is due to the non-linear heat diffusion as well as to the phase transformation during the SLS process. It should also be noted that the processing parameters must be chosen with care to avoid excessive heating and degradation of the sintered material. To do this, the modeling tool can also be used to

develop optimal SLS processing parameters.

The author [3] The use of combined experimental and numerical developments has been shown to provide useful information concerning the matter-laser coupling, the characteristics of the molten polymer and the thresholds of use during the SLS process. For the two polymer powders studied on an SLS designed, the power measurements by incremental canapes of powder enabled us to determine the law of transmission of the powder, multiplied by an absorption-diffusion factor $\mathrm{K}$, as a source of heat calculations volume. They showed that such numerical calculations correctly reproduced experimental depths of fusion using a coefficient $\mathrm{K}=0.4$, which indicates that most of the incident laser light $(60 \%)$ is reflected or scattered in the bed. powder. Finally, the timetemperature profiles were estimated numerically on the PEKK powder, and we made it possible to obtain temperature thresholds corresponding to a thermooxidative degradation of the polymer. In turn, this numerical approach made it possible to select the appropriate parameters to limit degradation and ensure optimal depths of fusion. However, and even if understanding and optimizing SLS on a dedicated open device seems to be an attractive way, manufacturing additive canapes has proven problematic with our experimental setup due to inconsistent scan speed values of the fusion path. This caused local overheating and significant deformation, which prevented complete densification of the SLS parts.

\section{Useful data}

The figure below shows a DSC analysis (DSC = Differential Scanning Calorimetry) for the commercial powder PA 12 LS. The nature of the sintering window between the start points of Tc and Tm is obvious.

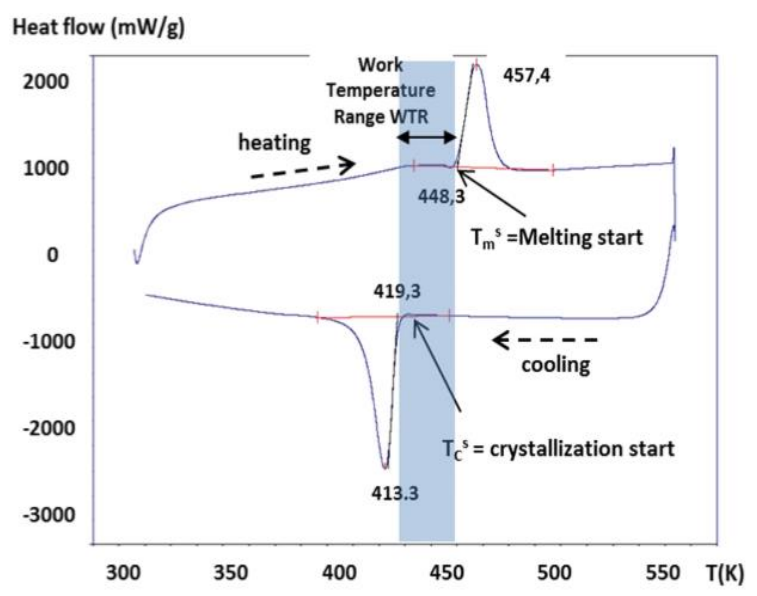

Fig. 2. Typical DSC thermogram with Typical DSC thermogram with the nature of the "sintering window" as the LS process temperature [defauchy 2013] 
Table 2. Examples of simulation models used in the literature

\begin{tabular}{|c|c|c|c|c|c|c|c|c|c|c|}
\hline Ref & Material & Software & $\begin{array}{l}\text { Model size : } \\
(\mathrm{mm})\end{array}$ & $\begin{array}{l}\text { Laser } \\
\text { power } \\
(\mathrm{w}) \\
.\end{array}$ & $\begin{array}{l}\text { Scan } \\
\text { speed } \\
(\mathrm{m} / \mathrm{s})\end{array}$ & $\begin{array}{l}\text { Hatch } \\
\text { space } \\
(\mathrm{mm})\end{array}$ & $\begin{array}{l}\text { Laser } \\
\text { diameter } \\
(\mathrm{mm})\end{array}$ & $\begin{array}{l}\text { Tint (pre- } \\
\text { heating) } \\
(\mathrm{K})\end{array}$ & $\begin{array}{l}\text { Tmax } \\
\text { (K) }\end{array}$ & $\begin{array}{l}\text { Type } \\
\text { of } \\
\text { Laser }\end{array}$ \\
\hline [3] & PA12 & $\begin{array}{c}\text { COMSOL } \\
\text { Multiphysique } \\
\text { TM4.2 }\end{array}$ & $\begin{array}{c}5 \mathrm{~mm} \times 4 \\
\mathrm{~mm} \times 1 \mathrm{~mm}\end{array}$ & 2.5 & 0.3 & - & $120 \mathrm{Um}$ & 440 & 480 & $\mathrm{CO}_{2}$ \\
\hline [6] & PA12 & Abaqus & $\begin{array}{c}\text { Cube de } \\
5 \times 0,8 \times 0,1 \\
\mathrm{~mm}\end{array}$ & $\begin{array}{c}3,846 \\
W,\end{array}$ & 1,257 & 0.15 & $0,4 \mathrm{~mm}$ & 455 & 496,3 & $\mathrm{CO}_{2}$ \\
\hline
\end{tabular}

However, it should be noted that the diagram in the figure is just an idealized representation of thermal reality since it is received with fixed heating and cooling rates $\left(10^{\circ} \mathrm{C}\right.$ / min) which never exist during LS treatment. Indeed, there are indefinite and difficult to control temperature change rates and especially the sintering temperature (Ts $=$ sintering process temperature) close to the start of crystallization means that the stimulation of crystallization moves towards higher temperatures for LS treatment.

\section{Conclusion}

Great efforts have been put in the area of SLS thermal analysis since the emergence of SLS technology, but there are still many areas for improvement that are needed, including in analysis and modeling of simulation and also in experimental measurement. A better understanding of the input energy model, which includes laser beam distribution, the ratio of energy penetration and material absorption; and thermal properties, such as thermal conductivity, density of the powder before and after laser scanning, are required.

As a future work, a detailed analysis of the laser effect will be considered. In addition, the coupling of meso mechanical properties with these crystallization and fusion results is proposed in order to obtain a better understanding of the development of warping of parts during an SLS construction and thus to validate the simulation results obtained.

\section{Reference}

1. A. Amado \& K. Wegener 2016, Characterization and modeling of non-isothermal crystallization of polyamide 12 and co-polypropylene during the SLS process,

2. Manfred Schmida, Konrad Wegener 2016, Additive Manufacturing: polymers applicable for laser sintering (LS),

3. Patrice Peyre, Yann Rouchausse 2015, Experimental and numerical analysis of the selective laser sintering (SLS) of pa12 and pekk semi-crystalline polymers,

4. Denis defauchy 2013, Thèse : Simulation du procède de fabrication directe de pièces thermoplastiques par fusion laser de poudre,

5. Alessandro Franco1, Michele Lanzett 2012, Experimental analysis of selective laser sintering of polyamide powders from energetic perspective.

6. L. Dong a, A.Makradi,2008, Simulation of the densification of semicrystalline polymer powders during the selective laser sintering process: application to nylon 12 .

7. T H C Childs and A E Tontowi 2001, Selective laser sintering of a crystalline and a glass-filled crystalline polymer: Experiments and simulations. 